\title{
Computação para Ensino Médio na Modalidade Semipresencial: Uma Experiência da Disciplina de Estágio Supervisionado
}

\author{
Máverick A. Ferreira ${ }^{1}$, Jakeline S. de Lima ${ }^{1}$, Higor M. Santos ${ }^{1}$, Edjanio Oliveira ${ }^{1}$, \\ Josefa Marciele F. do Nascimento ${ }^{1}$ \\ ${ }^{1}$ Universidade de Pernambuco, Campus Garanhuns (UPE) \\ CEP 55.294-902 - Garanhuns - PE - Brasil \\ \{amaverick70@gmail.com, jakelline29@gmail.com. higor.monteiro@upe.br, \\ edjanio.upe@gmail.com, marciele.upe@gmail.com\}
}

\begin{abstract}
This article aims to report the experience of a short course of introduction to programming in courses for high school students. Despite the programming education be a challenging activity, noted the great interest of many countries to include it into the school curriculum. In parallel to this, the courses education mode has spread widely and can assist in the process of teaching and learning. In this way, using tools and activities in order to provide a learning environment and attractive. The results of this experience reinforces the importance of computer education in basic education as a way to develop creativity and problem-solving ability, either from a distance or in person.
\end{abstract}

Resumo: Este artigo tem o objetivo de relatar a experiência de um minicurso de introdução a programação na modalidade semipresencial para alunos do Ensino Médio. Apesar do ensino de programação ser uma atividade desafiadora, observa-se o grande interesse de vários países em incluí-lo no currículo escolar. Em paralelo a isso, a modalidade de educação semipresencial tem se difundido largamente e pode auxiliar nesse processo de ensino e aprendizagem. Desse modo, utilizou-se ferramentas e atividades lúdicas visando proporcionar uma aprendizagem envolvente e atrativa. Os resultados dessa experiência reforçam a importância do ensino de Computação na educação básica, como forma de desenvolver a criatividade e habilidade de resolução de problemas, seja à distância ou presencialmente.

\section{Introdução}

Com o crescimento populacional, econômico e o advento das Tecnologias da Informação e Comunicação (TIC's), a sociedade tem passado por grandes transformações sociais e culturais, sejam estas direcionadas a hábitos, comportamentos ou valores. A realidade tecnológica na qual vivemos, nos faz repensar sobre o papel da escola diante da formação de cidadãos críticos e conscientes de sua função perante a sociedade atual. Diante disso, percebe-se a necessidade da escola em buscar novos métodos, condizentes com a realidade vivenciada pelo aluno. 
Neste aspecto, Gomes (2012) destaca as principais características desejáveis para o profissional do século XXI, tais como, o pensamento crítico, a capacidade de resolver problemas e a criatividade. Habilidades estas que podem ser alcançadas através do chamado Pensamento Computacional, definido por Blikstein (2008) como o ato de "usar o computador como um instrumento de aumento do poder cognitivo e operacional humano, aumentando a nossa produtividade, inventividade e criatividade". As discussões em torno da possibilidade de inserir o pensamento computacional na educação remete para um avanço do sistema de ensino atual. $\mathrm{O}$ seu uso tende a formar indivíduos com habilidades tecnológicas específicas, as quais se fazem necessárias para a sociedade pós-industrial [BLIKSTEIN, 2008].

No entanto, o ensino de Computação na educação básica brasileira encontra-se em um estágio onde apenas projetos isolados, promovidos por alunos e professores universitários, são colocados em prática nas escolas [FRANÇA et al, 2012; NETO et al, 2013]. Em paralelo a isso, progressos do ensino de Computação nas escolas podem ser verificados nos currículos utilizados na educação básica em Israel, Canadá e Estados Unidos. Esses países estão cada vez mais permitindo que a Computação alcance o estágio da educação imperativa. Nesta educação, mais importante que transmitir o conhecimento tecnológico, é desenvolver nos alunos o pensamento computacional [SCAICO, 2012].

Nesse aspecto, vale ressaltar a dificuldade de aprendizagem de conceitos relacionados à programação no âmbito acadêmico, causada muitas vezes, por déficits relativos a resolução de problemas, raciocínio e lógica [GOMES et al, 2012]. Considerando a complexidade referente ao aprendizado da Ciência da Computação, acredita-se que o desenvolvimento do Pensamento Computacional ainda na educação básica, além de implicar em benefícios cognitivos para o aluno, trará melhorias para o cenário da Computação na educação superior [GAL-EZER et al., 1999].

Capacitar-se independente de distância, estudar após as aulas presenciais e a possibilidade do aluno fazer seus horários de estudos são alguns dos fatores que têm contribuído para a grande adesão da educação a distância [BELLONI, 1999]. Outra modalidade que tem obtido bastante espaço por conciliar as boas práticas da educação presencial e a EaD é a educação semipresencial. Para Bertagnolli et al. (2008), o ensino semipresencial pode ter aulas a distância com até $20 \%$ da carga horária total do curso. Esta é considerada uma ótima alternativa atualmente porque além de manter laços afetivos entre professor-aluno e aluno-aluno, também permite um acompanhamento formal das atividades a distância ao longo do curso [VOIGT, 2007].

Neste contexto, o presente estudo, visa relatar um minicurso semipresencial de introdução a programação, vivenciado durante a disciplina de Estágio Supervisionado do curso de Licenciatura em Computação da Universidade de Pernambuco - Campus Garanhuns. O objetivo deste minicurso é evidenciar a possibilidade de ensinar conceitos básicos de Computação sob a perspectiva do ensino semipresencial, de forma a proporcionar um aprendizado divertido e ao mesmo tempo motivador em um público da educação básica. 


\section{Trabalhos Relacionados}

$\mathrm{Na}$ literatura é possível encontrar diversos trabalhos que apresentam um relato de experiência com o ensino de Computação na educação básica no Brasil. França, Silva e Amaral (2012) apresentam um relato de experiência de ensino de Computação envolvendo alunos do $9^{\circ}$ ano do ensino fundamental. Com o objetivo de promover a disseminação do pensamento computacional na educação, os conceitos básicos em torno da Ciência da Computação foram trabalhados baseando-se em atividades lúdicas, utilizando como apoio, a metodologia da Computação Desplugada e a plataforma de programação Scratch. Vale destacar, que ambas, tem um alto poder lúdico e atrativo, o que facilita a compreensão por parte dos alunos.

Costa et al. (2012) detalham a experiência de aplicação de atividades no ensino fundamental com o objetivo de incentivar a inclusão de conceitos computacionais do currículo escolar. Além disso, demostram o potencial da área para o exercício de habilidades cognitivas, abstração e resolução de problemas. Com o intuito de estimular o desafio através de uma competição saudável, a aplicação dos conceitos foram trabalhados por meio de uma gincana, composta por 4 atividades baseadas na metodologia da Computação Desplugada.

Diante desses trabalhos relacionados, o presente artigo busca incorporar meios e ferramentas que possibilitem o desenvolvimento do raciocínio lógico através dos conceitos básicos de introdução a programação de forma lúdica. Um grande diferencial deste trabalho é sua execução na modalidade semipresencial para o público da educação básica. Com isso, buscou-se oferecer meios para que a troca de conhecimento não se restringisse ao momento de sala de aula, expandindo assim o espaço de comunicação e aprendizado. Além disso, foram realizadas dinâmicas, atividades e utilização de softwares, tais como, Robomind e Mindstorm, com a intenção de trabalhar com exemplos práticos e vivenciados no dia-a-dia dos alunos.

\section{Metodologia}

Diante do planejamento com os três professores da disciplina de Estágio Supervisionado IV, do curso de Licenciatura em Computação, determinou-se que o público-alvo para o minicurso seriam alunos do primeiro ano do Ensino Médio. As atividades ocorreram no laboratório de informática da Universidade de Pernambuco - Campus Garanhuns e contaram com a participação de 16 alunos das Escolas: Estadual Jerônimo Gueiros, Estadual Eliza Coelho e Aplicação Ivonita Alves Guerra. Todas elas são escolas públicas da cidade de Garanhuns, distante $230 \mathrm{~km}$ de Recife-PE. Ressalta-se que as inscrições dos alunos participantes foram realizadas após divulgação presencial nas escolas supracitadas.

O minicurso semipresencial teve em seu total cinco encontros. Dos quais, três foram presencias com duração de 5 horas cada e dois encontros a distância, através do ambiente virtual Edmodo ${ }^{1}$, com duração de 2 horas cada, totalizando 19 horas de minicurso. O

\footnotetext{
1 Site do Ambiente Virtual Edmodo: https://www.edmodo.com/

${ }^{2}$ Site do ambiente de programação RoboMind: http://www.robomind.net/pt/
} 
Edmodo é um AVA com funcionalidades e características de uma rede social. Essa plataforma, além de organizar a sala de aula com atividades virtuais, permite aos professores trocarem experiências diretamente com o aluno a partir dos comentários de suas postagens. Além disso, ele permite o compartilhamento de materiais, sejam vídeos ou arquivos em PDFs [PORVIR, 2014].

Nesse contexto, ressalta-se que o minicurso enquadra-se como semipresencial com base na portaria $\mathrm{n}^{\mathrm{o}} 4.059 / 04$, a qual estipula que nesta modalidade de ensino até $20 \%$ das atividades podem ser realizadas a distância. Essa portaria define ensino semipresencial:

“[...] como quaisquer atividades didáticas, módulo ou unidades de ensinoaprendizagem centrados na autoaprendizagem e com a mediação de recursos didáticos organizados em diferentes suportes de informação que utilizem tecnologias de comunicação." [BRASIL, 2004].

É válido destacar que o WhatsApp também foi utilizado como um espaço de comunicação frequente possibilitando a discussão rápida dos conteúdos, informações sobre entrega de atividades, além de ter sido um meio para sugestões e críticas vindas dos alunos para possíveis melhorias do minicurso. Com essa ferramenta, pode-se afirmar que os alunos tiveram a possibilidade de aproveitar bem mais do que as 19 horas formais definidas inicialmente. O planejamento e organização do minicurso caracterizou-se em três etapas: Divulgação do Minicurso, Seleção de Ferramentas e Definição das Aulas.

Divulgação: $O$ objetivo foi despertar o interesse dos potenciais alunos pelo minicurso ofertado. Durante a divulgação presencial nas escolas, foram realizadas apresentações em sala de aula, assim como foram deixados panfletos e cartazes. As matrículas foram efetuadas através de um formulário online, criado no Google Drive. Criou-se ainda uma Fanpage com o intuito de investir na divulgação online, nesta também era possível encontrar o formulário para inscrição;

Seleção de ferramentas: Foi realizada uma pesquisa com o objetivo de identificar as principais ferramentas voltadas para o ensino de programação que abordam os seguintes requisitos: ter características lúdicas e possibilitar a abordagem dos conceitos com baixo nível de complexidade. Foram encontradas as seguintes ferramentas: Scratch, SuperLogo, Light-Bot, Kodu, entres outras. No entanto, devido ao limite de tempo para realização do curso, selecionou-se as seguintes ferramentas: $i$. Light-Bot: Um jogo online que permite ao usuário controlar um robô através de um conjunto de passos definidos para que este alcance o objetivo proposto. ii. RoboMind ${ }^{2}$ : É um ambiente de programação que permite o usuário se familiarizar com os conceitos básicos de Ciência da Computação programando seu próprio robô; e iii. Mindstorm ${ }^{3}$ : O Kit de robótica educacional Lego Mindstorms possibilita que o usuário crie e programe seu próprio robô utilizando peças mecânicas simples. Permite que o aluno trabalhe de forma prática desenvolvendo habilidades, tais como o raciocínio lógico e resolução de problemas.

\footnotetext{
${ }^{2}$ Site do ambiente de programação RoboMind: http://www.robomind.net/pt/

${ }^{3}$ Site do Minsdtorm: http://www.lego.com/en-us/mindstorms/?domainredir=mindstorms.lego.com
} 
Definição de aulas (presenciais e à distância): Por se caracterizar como um minicurso semipresencial, o planejamento foi categorizado em aulas presenciais e a distância. Para as aulas presenciais, foram definidos os conteúdos teóricos a serem trabalhados em cada aula e a construção de quatro dinâmicas inspiradas na metodologia Computação Desplugada, uma para cada encontro presencial. A seguir, as dinâmicas são apresentadas.

Dinâmica i - Passo a Passo: teve como objetivo verificar os primeiros conhecimentos adquiridos pelos alunos em relação à lógica de programação e algoritmos. Dinâmica ii - Jogo perguntas e respostas: teve como objetivo testar e reforçar conhecimentos adquiridos na aula anterior. Dinâmica iii - Tipos de Dados: seu objetivo foi analisar e organizar os dados de acordo com seu tipo. Dinâmica iv - Decidindo e estruturando: seu objetivo foi estimular a organização do pensamento sequencial e lógico na resolução de problemas.

Para a realização das aulas a distância foi definido inicialmente o ambiente virtual a ser utilizado, neste caso o Edmodo. Com o objetivo de auxiliar os alunos em seus estudos, percebeu-se a necessidade de conceder materiais que servissem de complemento aos assuntos trabalhados nas aulas presenciais. Dessa forma, os materiais complementares foram disponibilizados através de vídeo-aulas, apostilas e hiperlinks.

\section{Minicurso de Introdução a Programação}

O minicurso, na modalidade semipresencial, teve duração de três semanas com três encontros presencias realizados nos dias 05, 12 e 19 de novembro de 2014, intercalados por dois a distância realizados nos dias 07 e 14 . Além desses encontros previamente definidos, ressalta-se que os alunos interagiram entre si e entre os tutores durante todos os dias através do grupo criado no Whatsapp.

\subsection{Aulas Presenciais}

A primeira aula presencial teve como objetivo abordar os conteúdos teóricos presentes na Tabela 1. Inicialmente, foi explicado aos alunos o objetivo geral do curso, seguido de uma breve explicação acerca do funcionamento do Edmodo na tentativa de minimizar possíveis dificuldades no decorrer do curso.

Tabela 1. Conteúdos Primeira Aula Presencial

\begin{tabular}{|c|c|}
\hline $\begin{array}{c}1^{\mathrm{o}} \text { aula } \\
\text { presencial }\end{array}$ & $\begin{array}{c}\text { i. Lógica de programação; ii. Conceito de algoritmos; iii. Conceito de Softwares; iv. } \\
\text { Dados x informações; } \mathbf{v} \text {. Representação de dados; vi. Conceito de variáveis. }\end{array}$ \\
\hline
\end{tabular}

Após a apresentação inicial, foi lecionado os conteúdos "i" e "ii" dispostos na Tabela 1. Logo em seguida, a primeira dinâmica denominada de "Passo a Passo" foi realizada. Solicitou-se aos participantes que criassem a sequência de passos que executam no percurso de suas casas até a escola. Posteriormente, as respostas foram comparadas e discutidas em sala. Durante as discussões, foi possível perceber que todos os alunos, apesar das peculiaridades no trajeto casa-escola, raciocinaram corretamente a sequência de passos. Ainda neste, ficou claro que para a maioria foi uma "surpresa" saber que o computador 
também funciona seguindo essa mesma lógica. Diante disso, destaca-se o questionamento de uma aluna ao fazer uma analogia a uma situação cotidiana: "Quer dizer que quando vou acessar o facebook, o computador estará seguindo uma sequência?”.

Após a apresentação dos assuntos "iii" e "iv", realizou-se uma atividade no jogo online Light-Bot com objetivo de fortalecer a importância da sequência de passos devidamente planejados para alcançar determinados objetivos. De forma unânime, notou-se o entusiasmo dos alunos perante a ludicidade desta ferramenta. No último ciclo da primeira aula, foram abordados os conteúdos "v" e "vi". Em seguida, trabalhou-se com o programa Mindstorm com a intenção de consolidar a aprendizagem acerca de estruturas de repetição.

Dividiu-se a turma em três grupos, os quais tinham como finalidade utilizar a lógica de modo a fazer o robô da Lego andar para frente, para trás, direita e esquerda. Ressalta-se que todos os grupos tiveram sucesso nesta atividade, pois conseguiram repetir por inúmeras vezes instruções que remeteram a execução dos passos predefinidos para a atividade.

A Tabela 2 demonstra os conteúdos teóricos apresentados na segunda aula presencial. Ressalta-se que a aula iniciou fazendo-se uma revisão dos conteúdos da semana anterior.

Tabela 2. Conteúdos Segunda Aula Presencial

\begin{tabular}{|c|c|}
\hline $\begin{array}{c}2^{\mathbf{o}} \text { aula } \\
\text { presencial }\end{array}$ & $\begin{array}{c}\text { vii. Constantes; viii. Expressões aritméticas; ix. Operadores relacionais; x. Operadores } \\
\text { lógicos; xi. Comandos de atribuição; xii. Estrutura sequencial; xiii. Comandos de decisão. }\end{array}$ \\
\hline
\end{tabular}

Após lecionados os assuntos "vii", "viii" e "ix", realizou-se a dinâmica denominada "Jogo perguntas e respostas". Nesta dinâmica, dividiu-se a turma em 2 grupos, "equipe A" e "equipe B", dentro de uma caixa foram inseridas 20 perguntas relacionadas ao conteúdo visto até então. A cada rodada um grupo retirava uma pergunta, após discussão entre seus membros, a equipe respondia. Em caso de erro, o grupo adversário receberia a pontuação estipulada em 10 pontos a cada fase. O clima de competição presente nesse momento demonstrou a importância de ensinar-se Computação através de atividades em que o aluno seja um agente ativo, e não passivo.

Para começar o segundo ciclo da aula, explicou-se os conceitos "x" e "xi". Logo após, foi aplicada a dinâmica "Tipos de dados" da seguinte maneira: foram colocadas 4 caixas em uma mesa, cada caixa identificada com os nomes dos tipos de dados abordados no curso, sendo eles: inteiro, booleano, caractere e real, como mostra a Figura 1.

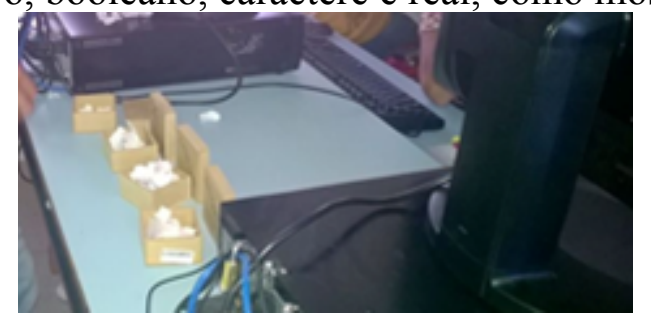

Figura 1. Caixas utilizadas na dinâmica "Tipos de dados"

Para consolidar a dinâmica, foram entregues perguntas aos alunos, tais como: (1) “Qual sua média escolar?”; (2) “Qual o seu sexo?”; (3) "Qual o seu sonho profissional?”; (4) "Qual sua idade?"; (5) "Seu monitor está ligado?”. Observa-se que as perguntas 
propiciam respostas, as quais se referem a diferentes tipos de dados. Ao analisar a distribuição das respostas, notou-se que a maioria depositou as respostas de caráter booleano na caixa com referencial caractere. No entanto, atribuiu-se tais erros ao fato de que as respostas relacionadas a pergunta "Seu monitor está ligado?" se deram de forma descritiva, quando os mesmos haviam associado tipo booleano apenas a verdadeiro e falso.

$\mathrm{Na}$ última parte da aula, os assuntos "xii" e "xiii" foram apresentados. Em sequência, realizou-se uma atividade com o RoboMind, conforme ilustrado na Figura 2. O objetivo foi enfatizar que um algoritmo é composto por uma sequência de passos lógicos. Nessa atividade, o aluno deveria atribuir uma sequência de comandos a um robô para movê-lo de um ponto a outro do cenário com base nas instruções solicitadas.

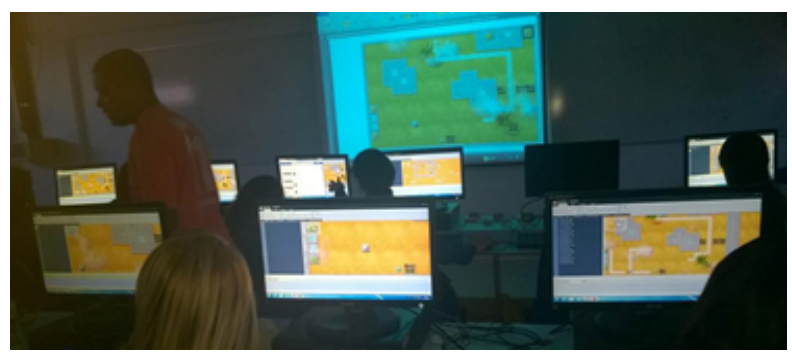

Figura 2. Atividade com o RoboMind

Todos os participantes obtiveram êxito durante essa atividade, realizando-a com uma certa facilidade. Notou-se que os mesmos conseguiram diferenciar de forma implícita as estruturas de repetição com e sem sentinela. Tal conclusão se refere a comentários proferidos por alguns alunos durante a realização da atividade, por exemplo, "Devemos contar e depois definir quantas vezes será preciso fazer o robô andar ou devemos colocar para repetir até atingir o objetivo?". A partir deste exemplo, nota-se que os participantes entenderam a diferença entre a estrutura em que definimos quantas vezes determinado código será repetido e a estrutura em que é a iteração acontecerá até que uma condição seja alcançada. A terceira aula presencial apresentou os conteúdos demonstrados na Tabela 3. Nesta também foi realizada uma revisão dos conteúdos e atividades da semana anterior.

\section{Tabela 3. Conteúdos Terceira Aula Presencial}

\begin{tabular}{c|l}
$3^{\circ}$ aula & $\begin{array}{l}\text { xiv. Estrutura de condição; xv. Estrutura de repetição; xvi. Estrutura de seleção simples; } \\
\text { presencial }\end{array}$ \\
xvii. Estrutura de seleção composta; xviii. Estrutura encadeada e múltipla.
\end{tabular}

Para começar a aula, os conteúdos "xiv" e "xv" foram apresentados e, em seguida, fez-se uso da dinâmica "Decidindo e estruturando". Com a turma separada em 3 grupos, a realização desta atividade se concentrou em expor blocos com algoritmos desorganizados. Para organizar os blocos, os alunos buscaram discutir e refletir resultando na organização de forma sequencial e lógica dos algoritmos. Posteriormente os assuntos "xvi" e "xvii" foram discutidos em sala e uma atividade com o RoboMind foi realizada para consolidar de forma prática. Devido a complexidade dos conceitos associados à estrutura de condição e repetição, foram utilizados 2 mapas do RoboMind. 
No primeiro mapa (passBeacons1.map) ${ }^{4}$, a meta do aluno era passar para o lado esquerdo do mapa, o qual existe alguns objetos impedindo a passagem do robô. Com isso, o aluno utilizou estruturas condicionais e de repetição para retirar os obstáculos e andar até o objetivo. O último aluno alcançou a meta do primeiro mapa em 21 minutos. Por sua vez, o segundo mapa (changeBelt12.map) ${ }^{5}$ exigiu dos alunos a utilização dos mesmos conceitos do mapa anterior. No entanto, atentou-se para diferenciação de estruturas de repetição por sentinela e por comparação. Apesar da complexidade das estruturas condicionais e repetitivas, todos os alunos, conseguiram realizar a atividade em ambos os mapas. $\mathrm{O}$ último aluno terminou o mapa 2 em 24 minutos.

Em seguida, o conteúdo "xviii”" foi apresentado aos alunos. Por fim, utilizou-se o software Mindstorm para programar um robô da lego. Tal dinâmica promoveu uma gincana entre 2 grupos, onde cada grupo ficou responsável por comandar um robô. A atividade consistiu em uma corrida com os robôs, em uma pista montada em linha reta com fitas adesivas. O objetivo do robô era sair da largada e parar exatamente na linha de chegada ${ }^{6}$. Ressalta-se que em meio ao clima de competitividade e descontração, ambos os grupos conseguiram atingir o objetivo.

\subsection{Aulas a distância}

Diante da necessidade de expandir o momento de aprendizado para fora da sala de aula, criou-se um espaço dentro do ambiente virtual Edmodo com o objetivo de compartilhar materiais e acompanhar os alunos durante seus estudos. É importante destacar que os PDFs das aulas presenciais, como também as atividades extras, eram postadas após os encontros presenciais no ambiente. As atividades eram postadas de acordo com os assuntos trabalhados nos encontros presenciais. Nestas, os alunos teriam 24 horas a contar da postagem para realização da atividade solicitada, podendo assim, usar o material como auxílio. Ressalta-se que foram produzidas duas vídeo-aulas referentes aos conceitos de lógica e variáveis.

No total, três atividades foram postadas: uma webquest composta por 5 questões de lógica de programação; uma tarefa com o software light-Bot, trabalhando com algoritmos e raciocínio lógico; e um quiz composto por 7 questões abordando todos os conteúdos trabalhados. As duas primeiras atividades foram aplicadas na primeira semana a distância e a terceira atividade aconteceu na segunda semana a distância. Além dessas atividades, os alunos podiam postar dúvidas referentes ao assunto no ambiente, os tutores reversaram todos os dias para acompanhar os alunos e as atividades solicitadas.

\section{Considerações Finais}

Diante do cenário tecnológico atual, acredita-se que inserir a Computação na educação básica, enquanto ciência, contribui para o desenvolvimento de habilidades essenciais aos

\footnotetext{
${ }^{4}$ Disponível em: https://www.dropbox.com/s/unux43fxsvfik6a/passBeacons1.png? $\mathrm{dl}=0$

${ }^{5}$ Disponível em: https://www.dropbox.com/s/nwnpmf77kps6czc/changeBelt12.png?dl=0F

${ }^{6}$ Disponível em: https://www.dropbox.com/s/69y4h23bfc7dwuo/Atividade_Mindstorm.jpg?dl=0
} 
alunos do século XXI. O presente artigo relatou uma experiência de ensino dos conceitos básicos de programação para alunos do Ensino Médio, por meio de um curso semipresencial e com abordagem lúdica. Com isso, foi possível observar o potencial das ferramentas lúdicas para a aprendizagem dos conteúdos propostos. Além de evidenciar a eficácia de utilização do Edmodo e do Whatsapp para fins educativos.

Foi perceptível também os benefícios de ensinar Computação por meio de ferramentas e atividades lúdicas, seja presencialmente ou a distância. Tal conclusão encontra-se fundamentada na motivação e facilidade de associação dos conceitos ensinados, demonstrados pelas falas dos alunos no decorrer do curso. Uma aluna afirmou: "Achei as aulas bem legais. Diferentes das aulas da escola. Aprendi bastante e nem notei o tempo passar!". Aponta-se como principal limitação deste trabalho a curta duração do minicurso, pois apesar dos resultados positivos, acredita-se que sua aplicação em um período mais longo possibilitará uma análise mais precisa, principalmente acerca das aulas à distância. Ressalta-se que esse período foi definido pelos professores da disciplina de Estágio Supervisionado do curso de Licenciatura em Computação.

Segundo o Manual de Estágio Supervisionado das Licenciaturas da UPE, o componente curricular Estágio Supervisionado deve compreender os eixos Ensino, Extensão e Pesquisa [UPE, 2015]. Dessa forma, o Ensino foi abordado no planejamento e execução das aulas desse minicurso semipresencial. A Extensão caracteriza-se pelo fato de proporcionar essa experiência para alunos de Ensino Médio das escolas públicas da cidade de Garanhuns. Por fim, a Pesquisa influenciou a busca pelas ferramentas, conteúdos teóricos sobre Computação e teve como resultado a própria escrita deste artigo científico.

Como dificuldades a serem destacadas na perspectiva dos Licenciandos em Computação, destacam-se o quão difícil é manter os alunos engajados durante as aulas presenciais e, principalmente a distância. As atividades e dinâmicas lúdicas agiram como um elemento que contribuiu para motivar os participantes ao longo minicurso. Além disso, enfatiza-se a inexperiência dos licenciados nessa modalidade de ensino. Considera-se que essa iniciativa teve contribuições importantes tanto para os alunos do minicurso que nunca tinham visto conceitos de programação, como também para os Licenciandos em Computação. Observou-se que o contato com a sala de aula, em especial com a modalidade de educação semipresencial, proporcionou aos integrantes as práticas docentes ainda no âmbito da graduação. Este fator é extremamente importante por se tratar de um curso de Licenciatura.

Por fim, sugere-se como trabalhos futuros: a realização de um curso mais extenso e com a ampliação do público-alvo; a inclusão de plataformas de desenvolvimento de jogos educativos na ementa do curso, como por exemplo, Game Maker ${ }^{7}$; e possibilitar aos alunos a aplicação dos conceitos de Computação na resolução de problemas das disciplinas do currículo escolar, tais como, matemática, geografia, física, etc.

\footnotetext{
${ }^{7}$ Site da plataforma Game Maker: https://www.yoyogames.com/studio
} 


\section{Referências}

Brasil (2004) Portaria no 4.059 de 10 de dezembro de 2004, Brasília, p. 1.

Belloni, M. (1999) Educação a distância. Coleção Educação Contemporânea, Ed Autores Associados, 115 pág.

Bertagnolli, S. C., et al. (2008) Potencialidades e Desafios da Modalidade Semipresencial. Novas Tecnologias na Educação, v. 6, n.1, pág. 1-10.

Blikstein, P. (2008) "O Pensamento Computacional e a Reinvenção do Computador na Educação". Disponível em: <http://bit.ly/11XlbNn>. Acesso em: 16 de março de 2015.

Costa, T. et al. (2012) "Trabalhando Fundamentos de Computação no Nível Fundamental: experiência de Licenciandos em Computação da Universidade Federal da Paraíba". XX Workshop de Educação em Computação - WEI. Curitiba, PR, Brasil.

França, R., Silva, W., Amaral, H. (2012) "Ensino de Ciência da Computação na Educação : Experiências, Desafios e Possibilidades". In: Anais XX Workshop de Educação em Computação - WEI. Curitiba, PR.

Gal-Ezer, J.; Harel, D. (1999) "Curriculum for a high school computer science curriculum". Computer Science Education 9(2), p. 114-147.

Gomes, G. et al. (2012) "Dificuldades na aprendizagem da programação no ensino profissional - perspectiva dos alunos". In: Anais II Congresso Internacional TIC e Educação, Lisboa, Portugal, pág.: 438-448.

Gomes, P. (2012). "Conheça as competências para o século 21”. Disponível em $<\mathrm{http}$ :/porvir.org/porpensar/conheca-competencias-para-seculo-21/20120814>. Acesso em: 13 de Mar. de 2015.

Neto, S. et al. (2013) Jogos Educacionais como Ferramenta de Auxílio em Sala de Aula. In: Anais XIX Workshop de Informática na Escola (WIE 2013), Campinas - SP, pág. 130139.

PORVIR (2014). "Rede social diminui solidão de professor". Disponível em: $<$ http://porvir.org/porcriar/rede-social-gratis-ajuda-na-formacao-deprofessor/20140217>. Acesso em: 23 de Mar. de 2015.

Scaico, P. et al. (2012). Um Relato de Experiências de Estagiários da Licenciatura em Computação com o Ensino de Computação para Crianças. Revista Novas Tecnologias RENOTE, v.10, n.3.

UPE (2015) "Manual de Estágio Supervisionado das Licenciaturas da UPE - Campus Garanhuns". Disponível em: <http://www.upe.br/garanhuns/wpcontent/uploads/2014/10/MANUAL-EST\%C3\%81GIO-LICENCIATURAS-

GARANHUNS-2015.pdf > . Acesso em: 20 de abril de 2015.

Voigt, E (2007) A Ponte Sobre o Abismo: Educação Semipresencial como Desafio dos Novos Tempos. Estudos Teológicos, vol 47, n 2. 